\title{
Embolia aérea maciça: tratamento, com sucesso, pela perfusão retrógrada
}

\author{
Sérgio Almeida de OLIVEIRA*, Paulo Borges SANTANA*, Januário M. SOUZA*
}

RBCCV

\begin{abstract}
OLIVEIRA, S. A.; SANTANA, P. B.; SOUZA, J. M. - Embolia aérea maciça: tratamento, com sucesso, pela perfusão retrógrada. Rev. Bras. Cir. Cardiovasc., 2(1):61-63, 1987

RESUMO: Os autores relatam o caso de paciente que teve embolia aérea maciça, durante operação para substituição da valva mitral. Este acidente foi tratado por técnica de perfusão venosa retrógrada, com aspiração da aorta ascendente, estando o paciente em hipotermia de $28^{\circ} \mathrm{C}$. A recuperação foi excelente, sem seqüelas neurológicas. Os autores acreditam que o emprego de mecanismo automático de desligamento da bomba, quando o nivel do reservatório arterial atingir o ponto considerado crítico, poderá ser de valor na profilaxia deste acidente.
\end{abstract}

DESCRITORES: embolia aérea; perfusão retrógrada; circulação extracorpórea.

\section{INTRODUÇÃO}

Embolia aérea maciça, durante operação corn emprego da circulação extracorpórea, é complicação grave, podendo ser causa de lesão cerebral, ou mesmo de morte do paciente. Muitas causas de embolia aérea foram descritas, assim como técnicas para evitá-las ${ }^{3,5}$. Nesta comunicação, relatamos o caso de uma paciente em que este acidente ocorreu, sendo tratada com sucesso, pela técnica de perfusão retrógrada com aspiração da aorta ascendente.

Relato do Caso: A. I. F., 46 anos, sexo feminino, portadora de dupla disfunção mitral, com predomínio de estenose. Relatava antecedentes de doença reumática na infância, evoluindo com estenose mitral. Foi operada em 1975, sendo realizada comissurotomia. Após permanecer assintomática por 10 anos, voltou a apresentar dispnéia inicialmente aos grandes esforços, evoluindo para disp- néia aos pequenos esforços, quando foi encaminhada ao nosso Serviço, sendo diagnosticado dupla disfunção mitral, com predomínio de estenose mitral, em grupo funcional III. Estudos ecocardiográfico e hemodinâmico confirmaram o diagnóstico clínico, sendo indicado o tratamento cirúrgico, o qual foi realizado no dia 17.06 .86 . O coração e os grandes vasos foram abordados, através de toracotomia mediana anterior (esternotomia), estabelecendo-se a circulação extracorpórea com canulação da aorta ascendente e do átrio direito. Utilizou-se conjunto coração-pulmão artificial, com bomba de roletes e oxigenador tipo bolhas, modelo DMG. O perfusato foi constituído de solução de Ringer-lactato $(1500 \mathrm{ml})$. A temperatura corpórea foi abaixada para $28^{\circ} \mathrm{C}$ (t. esofágica), sendo, então, pinçada a aorta ascendente logo acima das artérias coronárias. $\mathrm{O}$ átrio esquerdo foi incisado anteriormente às veias pulmonares direitas, expondo-se a valva mitral, que se apresentava calcificada, com estenose e insuficiência, sendo removida e implan-

Trabalho realizado no Serviço de Cirurgia Cardiovascular do Prof. Sérgio Almeida de Oliveira, do Hospital da Beneficência Portuguesa. São Paulo, SP, Brasil.

- Do Serviço de Cirurgia Cardiovascular do Prof. Sérgio Almeida de Oliveira, do Hospital São Joaquim da Beneficência Portuguesa.

Entregue para publicação em 4 de abril de 1987.

Endereço para separatas: Sérgio Almeida de Oliveira. Av. Dr. Enéas Carvalho de Aguiar, 44. Divisão Cirúrgica. 05403 São Paulo, SP, Brasil. 
tada bioprótese heteróloga (válvula aórtica de porco) preservada em glutaraldeído (modelo Biocor M-31). Após a implantação da bioprótese, foi solicitado ao perfusionista que reduzisse a drenagem venosa, para facilitar o enchimento de ventrículo e átrio esquerdos, para ser testada a bioprótese mitral, após o restabelecimento dos batimentos cardíacos. Inadvertidamente, esvaziou-se o reservatório arterial do oxigenador, sendo injetado, na aorta, ar em quantidade não conhecida, durante aproximadamente 1 a 2 minutos. Identificado o fato e estando toda a linha arterial cheia de ar, a perfusão foi interrompida, o oxigenador foi enchido com 1 litro de solução Ringer-lactato e a linha arterial foi vinculada à cânula direita, iniciando-se um período de perfusão retrógrada, sendo a paciente colocada em posição de Trendelenburg. A cânula da aorta foi ligada a um dos aspiradores. A perfusão retrógrada foi mantida, até que a aspiração na aorta passou a retirar sangue, ao invés de ar. Neste momento, as linhas venosa e arterial foram reposicionadas, restabelecendo-se a circulação extracorpórea clássica. O tempo gasto para a realização desta manobra foi de 5 minutos. A pinça da aorta foi removida, reiniciando-se a perfusão coronária (parada cardíaca anóxica de 27 minutos), com o restabelecimento espontâneo dos batimentos cardíacos. A válvula mitral foi testada, estando eficiente. $O$ átrio esquerdo foi suturado e, após aquecimento da paciente para $36,5^{\circ} \mathrm{C}$, a circulação extracorpórea foi interrompida, mantendo a paciente em boas condições hemodinâmicas. O mediastino foi drenado, realizadas a aproximação do esterno e sutura dos planos superficiais.

A evolução pós-operatória transcorreu sem complicaçōes. Duas horas após, já na Unidade de Terapia Intensiva, a paciente estava acordada e respirando espontaneamente. Recebeu alta hospitalar no 8 : dia do pós-operatório, sem qualquer complicação neurológica.

\section{COMENTÁRIOS}

Embolia aérea maciça durante a circulação extracorpórea, é, felizmente, uma complicação rara, mas potencialmente grave. As causas desta complicação são várias, tendo sido enumeradas por MILLS \& OCHSNER ${ }^{3}$ : a) desatenção ao nivel do reservatório; b) direção da bomba arterial, ou da tubulação em posição reversa; c) restabelecimento inesperado dos batimentos cardíacos; d) manobras inadequadas de remoção de ar das cavidades cardiacas, após cardiotomia; e) aspiração profunda e intensa das artérias pulmonares; f) oxigenador com defeito; g) uso do reservatório pressurizado para cardiotomia; h) desprendimento inadvertido do oxigenador, durante a perfusão.

Acreditamos que as complicações neurológicas resultantes da embolia aérea possam depender mais de parada circulatória provocada pela embolia coronária e conseqüente parada cardíaca. Até que seja possivel restabelecer, de modo adequado, a circulação, através de diferentes métodos, o tempo de anóxia cerebral, sendo superior a alguns minutos, levará a seqüela neurológica. No presente caso aqui relatado, assim como nos relatos de HENDRIKS et alii ${ }^{1}$ e STARK et alii ${ }^{4}$, o acidente ocorreu estando os pacientes em hipotermia de $28^{\circ} \mathrm{C}$ em nosso paciente, e de $20^{\circ} \mathrm{C}$ nos dos autores acima citados, havendo, em todos, recuperação sem seqüela neurológica. O método de perfusão retrógrada com aspiração da aorta e perfusão venosa, com paciente em posição de Trendelenburg, descrita por MILLS \& OCHSNER ${ }^{3}$, oferece boa possibilidade de êxito, especialmente se o acidente ocorrer estando o paciente em hipotermia, ou se as manobras forem realizadas com grande agilidade.

A utilização de dispositivo automático de desligamento da bomba arterial, quando o nível sangüíneo do reservatório arterial atingir um ponto considerado crítico, parece ser medida valiosa, conforme JAZBIK et alii ${ }^{2}$, com benefícios evidentes.

RBCCV

OLIVEIRA, S. A.; SANTANA, P. B.; SOUZA, J. M. - Massive air embolization successfully treated by reversed perfusion. Rev. Bras. Cir. Cardiovasc., 2(1):61-63, 1987

ABSTRACT: The authors report a case of massive air embolization occuring while an operation for mitral valve replacement has been performed. The air entered the aorta due to inattention to reservoir level. At that time the esofaged temperature was $28^{\circ} \mathrm{C}$. The accident was successfully corrected using the reversed perfusion. There were no neurological sequelae and the post-operative evolution was uneventful.

DESCRIPTORS: air embolization; reversed perfusion; extracorporeal circulation. 
OLIVEIRA, S. A.; SANTANA, P. B.; SOUZA, J M. - Embolia aérea maciça: tratamento com sucesso, pela perfusão retrograda. Rev. Bras. Cir. Cardiovasc., 2(1):61-63, 1987.

\section{REFERÊNCIAS BIBLIOGRÁFICAS}

1 HENDRIKS, F. F. A.; ROGERS, J. J. C.; Ia RIVIÈRE, A. B. de; HUYSMANS, H. A.: BROM, G. A. - The effectiveness of venoarterial perfusion in treatment of arterial air embolism during cardiopulmonary bypass. Ann. Thorac. Surg., 36 (4): 433-436, 1983.

2. JAZBIK, W. - Coração-pulmão artificial. Rio de Janeiro, 1970. p. 18 (Tese Livre-docência - Faculdade de Medicina da UFRJ).
3. MILLS, N. L. \& OCHSNER, J. L. - Massive air embolism during cardiopulmonary bypass: causes, prevention. and management. J. Thorac. Cardiovasc. Surg., 80 (5): $708-717,1980$.

4. STARK, J. \& HOUGH, J. - Air in the aorta: treatment by reversed perfusion. Ann. Thorac. Surg., 41 (3): 337-338, 1986.

5. STONEY, W. S.; ALFORD Jr., W. C.; BURRUS, G. R.; GLASSFORD Jr., D. M.; THOMAS Jr., C. S. - Air embolism and other accidents using pump oxygenators. Ann. Thorac. Surg., 29 (4): 336-340, 1980. 